\title{
The Development of Learners' Autonomy through Blended Learning Activities
}

\author{
Anna Mrajca ${ }^{1}$ and Krzysztof Polok ${ }^{2}$ \\ ${ }^{1,2}$ University of Bielsko, Biala, Poland \\ 1anna.mrajca@gmail.com, ${ }^{2}$ sworntran@interia.pl
}

\begin{abstract}
The study investigates the effect of blended learning activities on the development of learners' autonomy as well as the influence of the level of learners' autonomy on their writing skills. During the research, a quasi-experimental study was conducted, involving three experimental groups and a control one. The participants were 57 Polish secondary school students. The members of the experimental groups were subjected to three different types of blended learning treatment, namely flipped classroom, project work, and individual WebQuests whereas the control group was taught traditionally. The intervention lasted for three months. The data was collected with the use of a learner's autonomy questionnaire and writing tasks, which were administered in each of the groups. The quantitative data thus obtained was analyzed with the use of one-way and two-way ANOVA. The results were inconclusive as the findings demonstrated that the flipped classroom group and the WebQuest group had a significantly higher level of autonomy after the intervention, whereas the project workgroup increase in the level of autonomy was not statistically significant. The findings concerning writing abilities evidenced that only the WebQuest group members' skills had improved. The most important limitation of the study was the fact that it was conducted during the remote education period caused by the COVID-19 pandemic. Nevertheless, based on the findings, some implications of the study were formulated.
\end{abstract}

Keywords: Learners' autonomy, Blended learning, Educational technologies, Teaching writing, EFL, ESL

\section{Introduction}

The past forty years were marked by numerous and rapid changes in the field of language teaching and learning. One of the most important alternations was the shift from teacher centeredness towards student-centeredness, the most significant indication of which was passing the responsibility for learning over to the learners. Taking charge of one's learning is a characteristic of an autonomous learner [1]. Learners' autonomy is believed to be one of the factors that affect effective language learning and acquisition to the greatest extent. Developing learner's independence has thus become the subject of extensive research in recent years. Bersin [2], on the subject, suggests that one of the most efficient ways of fostering learners' autonomy is $\mathrm{BL}$, which is typically understood as a combination of traditional instruction (performed by the teacher in class) and various technologies. The

Article history:

Received (October 1, 2021), Review Result (November 5, 2021), Accepted (December 15, 2021) 
present study was hence designed to investigate the issue of learners' autonomy in a blendedlearning environment.

\section{Autonomy in foreign language teaching}

In 1979, in his report concerning adult education, Henri Holec put forward a definition of autonomy which was to be widely referred to in the following years. He described it as the "ability to take charge of one's learning" [1]. As the definition might seem ambiguous, he further added:

To take charge of one's learning is to have, and to hold, the responsibility for all the decisions concerning all aspects of this learning, i.e.:

(a) Determining the objectives;

(b) Defining the contents and progressions;

(c) Selecting methods and techniques to be used;

(d) Monitoring the procedure of acquisition properly speaking (rhythm, time, place, etc.);

(e) Evaluating what has been acquired. (Holec, 1979, p.3)

There seems to be little doubt as to how to understand the abovementioned explanation. However, Holec [1] argued that the mere presence of a teacher does not prevent the students from taking responsibility for their learning. In a situation where decision-making is shared between teachers and learners, the probability of the latter taking charge of their studying is much higher. Thus, for an "autonomisation" process to take place, it is crucial for the learner to have a certain capacity, to know how to take charge of their learning and how to make adequate decisions regarding the process. However, the learning structure ought to make it possible for the learner to exercise control over the process as well. One of the most significant findings of the report compiled by Holec is the notion that autonomy cannot be perceived as a congenital feature. According to Holec [1], autonomy can be acquired either by natural means or, which seems to be particularly important for ELT teachers, by deliberate formal learning. The definition put forward by Holec was recognized by the teaching community and has also been the one the most commonly cited by other authors. Nevertheless, it has also been criticized for being incomplete and unclear. In Learner Autonomy 1: Definitions, Issues, and Problems by Little [3] argued that autonomy derives from various sources and has broad implications. However, discussing autonomy without a universal definition would be misleading. Thus, he decided to put forward a definition which he described as provisional: "Essentially, autonomy is a capacity - for detachment, critical reflection, decision-making, and independent action. It presupposes, but also entails, that the learner will develop a particular kind of psychological relation to the process and content of his learning [3]". He also noticed that autonomy is frequently equated with independence, especially from teachers. But people are social creatures and education, regardless of whether it is institutionalized or not, is a social process. Learners' ability of self-instruction often derives from interactions, not only with teachers but mostly with other learners. Similarly, to Holec [1], Little [2] pointed out that autonomy comes in different degrees, i.e., depending on the age of the learners, their language needs, what they achieved linguistically so far, etc. Moreover, he argued that gaining autonomy might be onerous and there is no guarantee that it will last. Benson [4] described autonomy as "the capacity to take control of one's learning". At first glance, the definition seemed to look like Holec's definition rephrased. However, it was further clarified by Huang [5] and Benson, who elaborated on the notions of "capacity" 
and "control" used in the definition. The capacity denotes the potential which an individual can make use of if he or she wishes. The researchers listed three components of the capacity, namely ability, desire, and freedom. He further discussed three aspects of 'control' over learning: learning management, cognitive processing, and learning content.

Sinclair [6], seeking a realistic definition of the notion, collected the most significant aspects that are characteristic for autonomy:

1. Autonomy is a construct of capacity.

2. Autonomy involves a willingness on the part of the learner to take responsibility for their learning.

3. The capacity and willingness of learners to take such responsibility are not necessarily innate.

4. Complete autonomy is an idealistic goal.

5. There are degrees of autonomy.

6. The degrees of autonomy are unstable and variable.

7. Autonomy is not simply a matter of placing learners in situations where they have to be independent.

8. Developing autonomy requires a conscious awareness of the learning process. - i.e., conscious reflection and decision-making; social and cultural awareness.

9. Promoting autonomy is not simply a matter of teaching strategies.

10. Autonomy can take place both inside and outside the classroom.

11. Autonomy has a social as well as an individual dimension.

12. The promotion of autonomy has a political as well as psychological dimension.

13. Autonomy is interpreted differently by different cultures. (Sinclair [6], p. 7-13)

Such a short-clear-cut list allows the EFL teachers to match the desirable level of autonomy to their students' needs as there are no "one-size-fits-all" solutions when it comes to developing certain levels of independence.

\section{Proactive vs. reactive autonomy}

Autonomy works differently in various conditions. Littlewood [7] analyzed how the concept of autonomy is understood in East Asian contexts. He found out that some teachers believed the autonomy to reflect western values, which made it unsuited for learners in Asian countries. Nevertheless, the teaching practice of some other teachers evidenced that belief to be wrong as during their classes Asian students showed readiness to work independently, with no help on the part of the teacher. Such an attitude towards learning may be perceived as a sign of autonomy.

Having analyzed the Asian context, Littlewood [7] introduced the idea for two types (or levels) of autonomy: proactive autonomy and a reactive one. Proactive autonomy, according to Littlewood [7], is the kind of autonomy that is meant while discussing the concept in western cultures. It entails taking responsibility for one's learning, establishing the learning objectives, selecting adequate methods and techniques for studying, and also evaluating the outcomes of the process. A student characterized by proactive autonomy controls the content 
of learning and chooses the way that the content should be handled to accomplish the educational goals. Reactive autonomy, on the other hand, maybe perceived as an initial step towards gaining a proactive one. It should be noted that developing reactive autonomy can also be an objective in its own right. A "reactive learner" does not set his or her own goals and directions, but when they are determined, the learner can plan and organize the studying to achieve them. Such a version of autonomy stimulates the students to learn designated material without being ordered to.

Littlewood [7] was not the first one to analyze and discuss a few "variants" of autonomy Dickinson [8] had done that over a decade before. In her work, she argued that, when it comes to dependency on the teacher, three levels of autonomy can be specified, namely programmed learning, semi-autonomy, and autonomy [8][9]. Yang [9] further clarified the definition of each of them. Programmed learning is a stage of total reliance on the teacher - the objectives are set and the methods and techniques of achieving them are also decided upon for the learners. In semi-autonomy, both the teachers and the learners share accountability for the learning process such as goals, techniques, materials, feedback, or instruction. The (complete) autonomy stage is the ultimate aim of language learning - a stage when the learners take full responsibility for their learning.

In Poland, the idea of the distinction between complete autonomy and semi-autonomy understood as the latter being the initial step for developing the former, resonated with the Polish academics and practitioners. The most obvious reason for which the teachers had not explored various levels of autonomy before was the one mentioned by Benson [10], namely the difficulty of giving the control over learning goals over to the learners within the framework of the national curriculum with its predetermined objectives. Allowing the students to have their aspirations and ambitions would seem risky, especially as the objectives had already been established and the teachers were held accountable for fulfilling them.

As it has been evidenced, succeeding in fostering autonomy does not have to entail gaining the "full" version of it. Therefore, Polish academics also focused on fostering semi-autonomy (sometimes referred to as "half-autonomy") in their work. Wilczyńska [11] (as cited in Batyra [12]) defined it as "the road to preparing learners to complete autonomy and to responsibility, decision, participation in managing one's learning process" (p. 53) or "due to numerous limitations in the process of developing autonomy in the Polish classroom context, the essence of the teacher's roles and actions in developing autonomy in learners and their active attitude towards learning". Hence, as Wiertlewska [11] notices, the term of "autonomisation" is frequently used about all the actions assisting the process of forming autonomy.

\section{Blended learning for developing autonomy}

The notion of blended learning is not new in language education - its premises and applications have been widely discussed for over three decades. Bersin [2] noted that BL derives from the corporate world where it was used for employee training. Since the corporate knowledge goes out of date expeditiously, the staff needs to be constantly trained in a fast and efficient manner. E-learning courses, which seemed to be a perfect option for overworked employees, turned out to be too easy to put off indefinitely. Thus, the BL model was introduced:

Blended learning is the combination of different training "media" (technologies, activities, and types of events) to create an optimum training program for a specific audience. The term "blended" means that traditional instructor-led training is being supplemented with other electronic formats [2]. 
The development of technology also influenced language learning. Numerous universities in Europe set up so-called self-access language learning centers, where students could work independently, making use of the newly-introduced technological tools, such as tape recorders, video recorders, CD players, photocopiers to name but a few. It is worth mentioning that, according to Tayabiknik et al. [13], the major problems connected with selfaccess centers and later on with e-learning were: the lack of face-to-face communication and the inhibition of the socialization process. BL seemed to be a perfect solution to those problems. It was understood as:

"A hybrid of traditional face-to-face and online learning so that instruction occurs both in the classroom and online, and where the online component becomes a natural extension of traditional classroom learning. (Colis et al., 2001 as cited in Tayabiknik et al.[13])",

It is widely believed that blended learning has a positive effect not only on the acquisition of language but also on learners' autonomy. The issue was analyzed by Marsh [14], who argued that including a "blend" in the teaching process can encourage students to work more independently. She listed the aspects of autonomous learning that might be influenced by working in a multimedia environment.

One of the most important changes which implementing BL entails is the fact, that the classes become more student-centered. Marsh [14] claimed that in the BL approach the educators focus their teaching not only on the abilities they believe that the students should acquire but also on the students' needs. The flexibility that is encouraged in the BL models enables the students to practice and master their time management skills. They need to be able to plan their independent learning sessions. Such abilities are the characteristics of an autonomous learner. Another important factor influenced by the hybrid of traditional and online teaching is the collaboration between students. The teachers repeatedly complain that pair and group work is excessively time-consuming and, as a consequence, they rarely incorporate such forms of work into their teaching practice. The use of technology is a solution to this problem as many collaborative projects can take place outside the classroom. Working in a blended model allows the students to self-evaluate to a much greater extent than working in the traditional one. Ardi [15] noted that using Schoology in the BL classroom positively affected the students' cognitive processing as they gave more thought to their learning processes and increased their metalinguistic awareness. Marsh [14] gave an example of tests that get checked automatically so the student gets instant feedback just as they finish writing. It gives the students a sense of achievement but they can also assess the progress that has been made. Finally, BL models of education influence learners' motivation to a significant degree. According to Marsh [14], the students are familiar with numerous online tools e.g., instant messaging, video call software, different forums, blogs but also social media. Incorporating them into the teaching practice can remarkably change the students' approach to learning. They may become more encouraged and ready to interact in the target language.

\section{The study}

\subsection{Participant}

The study was conducted in a secondary school in Poland. Convenience sampling was performed to select a group of students who were going to undergo the quasi-experimental treatment. There were 57 participants altogether divided into four groups, three experimental groups and a control group in the following manner: 
(a) The control group (referred to as CG), which consisted of 15 students who were taught with the use of traditional methods;

(b) The first experimental group (referred to as FC), which consisted of 12 students, who received the flipped classroom treatment;

(c) The second experimental group (referred to as PW), which consisted of 16 students and underwent the project work treatment;

(d) The third experimental group (referred to as WQ), which consisted of 15 students who were subjected to the WebQuest lesson format.

\subsection{Data collection and analysis}

The main research question was formulated as follows:

Does implementing a blended learning approach to teaching and learning English as a foreign language foster the development of learners' autonomy?

The subsequent main hypothesis was specified:

It is hypothesized that blended learning classroom activities enhance the development of autonomy in secondary school students.

It is believed that technology-enhanced instructions ought to help students to become more independent in the EFL classroom and outside of it. As autonomy comes in various stages, the learners can work in a full autonomy paradigm or a semi-autonomy paradigm. Moreover, numerous strategies can be applied by the teacher in pursuit of her students' autonomy. Therefore, the following sub-questions were put forward:

(1) Which type of learners' autonomy can be developed to a greater extent - reactive autonomy or proactive autonomy?

(2) Is the flipped class teaching model a valuable tool for fostering the growth of autonomy in secondary school students?

(3) Is the web quest teaching model a valuable tool for fostering the growth of autonomy in secondary school students?

(4) Is the introduction of collaborative technology-enhanced project work in the EFL classroom a valuable tool for fostering the growth of autonomy in secondary school students?

(5) Which of the three models of blended learning activities (flipped classes, WebQuests, or technology-enhanced project work) is most helpful while developing learners' autonomy?

The researchers sought to find the answers to the above-mentioned questions with the use of the autonomy questionnaire which was adapted from Pawlak [16].

Furthermore, the researchers intended to examine the effect of learners' autonomy level on the writing abilities of the students. Hence, the following research sub-question was formulated:

(6) What is the correlation between the level of autonomy of the learners and their writing competence?

To investigate the correlation between students' writing proficiency and their level of autonomy, we implemented a pre-test and a post-test in writing, which was later analyzed for compliance with the results drawn from the outcomes of the learners' autonomy questionnaire. It consisted of 15 Likert scale items where the responses range from 1 ("I strongly disagree") to 5 ("I strongly agree"). The students who participated in the pre-test 
were asked to complete the questionnaire again after the intervention phase was over. Thus, the results of the pre-test and post-test could be compared.

For each of the 15 questions from the questionnaire, the two-way ANOVA was performed to verify if the independent variables, i.e., the number of the questions and the fact of being a member of a given experimental group, affected the dependent variable, which in this case was the level of learners' autonomy. The results were then presented in the form of a table and contained the information if the data obtained is statistically significant or not. Then, for each statistically relevant outcome, the post hoc test, namely the Least Significant Difference (LSD) test was run to compare the treatment groups pairwise.

The first question from the learners' autonomy questionnaire was formulated in the following way: I can evaluate my progress in learning English. The ANOVA carried out proved the $p$-value to be .02714 which indicated that the result was significant at $p<.05$. The post hoc test results indicated that the Project Work group's (PW) score in pre-test question no. 1 differed significantly from the score achieved in post-test question no. 1 . There were no significant differences between the scores of the rest of the groups.

The second question that the students were asked to answer took the following form: I know my strengths and weaknesses when it comes to knowledge of the English language. Its ANOVA p-value was .0158 which indicated that the result was significant at $\mathrm{p}<.05$. The LSD test results showed that there were significant differences between the measurements (pre-test and post-test) only within the WebQuest (WQ) group. In the second measurement (post-test), no differences between the groups of students were observed.

The results obtained for the third statement (I often learn without the teacher's supervision (e.g., when watching films in English, doing additional exercises.) were not statistically significant.

The fourth statement from the learners' autonomy questionnaire was formulated in the following way: I can identify my own needs and set my own goals. The two-way ANOVA evidenced that there were significant differences between the group means as $\mathrm{p}<0.05$. Using the post hoc LSD test the researchers identified those differences. In two groups significant differences were observed in both measurements, namely flipped classroom and WebQuest groups. In the pre-test, there are relevant differences between two pairs of groups flipped classroom and project work as well as project work and WebQuest. In the post-test, the substantial difference was only observed between the score of the control group and the project group.

The results obtained for the fifth statement (I know when. where and how I learn the most easily.) were not statistically significant.

The sixth statement that the students were asked to answer took the following form: $I$ choose the materials on my own and do not limit myself to those recommended by the teacher. The ANOVA was performed. The p-value was .0263 $(<.05)$. The LSD test was conducted. Only in the flipped classroom group, significant results between the first and second measurements were observed. Within the first measurement, significant differences were observed between the values in the WebQuest group and the control group. No significant differences were found within the second measurement.

The seventh statement from the learners' autonomy questionnaire was formulated in the following way: I can evaluate the effectiveness of the way I learn and modify it. The p-value obtained in ANOVA was .0141 (<.05). The LSD test evidenced the significant differences between the measurements in two groups - in the flipped classroom and project workgroups. 
The results obtained for the eight statements (I try to solve the language problems (e.g., unfamiliar word. grammatical structure) I encounter on my own.) were not statistically significant.

The fifteenth and final statement from the learners' autonomy questionnaire was formulated in the following way: I can decide for myself what the most important thing during the lesson is to me. The two-way ANOVA showed that there were some differences between the results as $p=.035$. The LSD test was conducted, which evidenced that there were differences between the measurements in two groups - those are the flipped classroom and WebQuest groups.

The tenth statement from the learners' autonomy questionnaire was formulated in the following way: I try to look for opportunities to have to do the English language as often as possible outside the school (e.g., by reading magazines. watching English-language programs. etc.). The p-value obtained in ANOVA was .044 $(<.05)$. The post hoc test indicated that there were no differences between the measurements in any of the studied groups. Within measurement no. 1 (pre-test) significant differences were observed in the project workgroup compared to the control group. Within measurement no. 2 (post-test) significant differences were observed within the two pairs, namely flipped classroom and project work as well as project work and WebQuest.

The results obtained for the eleventh (I learn English even when it is not necessary e.g., during holidays.), the twelfth (When working in pairs and small groups. (I try to use English as often as possible.), the thirteenth (I know what techniques and strategies to use to learn and use English better.) and the fourteen (I treat learning failures as valuable new experiences. not as a reason to be discouraged.) statements were not statistically significant.

The fifteenth and final statement from the learners' autonomy questionnaire was formulated in the following way: I believe that in the future I will be able to become a fluent English speaker. The two-way ANOVA allowed us to conclude that there were some significant differences between the means in the studied groups. The LSD test evidenced that only one group showed a difference in the mean values between the pre-test and the post-test, namely the WebQuest group. Within the first measurement, it can be observed that the project workgroup differs significantly from each of the other three groups. Within the second measurement, no significant differences between the means in the studied groups have been noted.

Apart from the analysis of the ANOVA results for the individual questions, the researchers decided to run a one-way ANOVA to verify if there were any significant differences between the pre-test and the post-test scores between the learners. The outcome of the test evidenced that there were no statistically significant differences between the groups.

Table 1. One-way ANOVA for the pre-test results in all four groups

\begin{tabular}{|c|c|c|c|c|c|c|c|c|c|}
\hline & $\begin{array}{c}\text { CG } \\
\text { mean }\end{array}$ & $\begin{array}{c}\text { CG Std. } \\
\text { Dev. }\end{array}$ & $\begin{array}{c}\text { FC } \\
\text { Mean }\end{array}$ & $\begin{array}{c}\text { FC Std. } \\
\text { Dev. }\end{array}$ & $\begin{array}{c}\text { PW } \\
\text { Mean }\end{array}$ & $\begin{array}{c}\text { PW Std. } \\
\text { Dev. }\end{array}$ & $\begin{array}{c}\text { WQ } \\
\text { Mean }\end{array}$ & $\begin{array}{c}\text { WQ Std. } \\
\text { Dev. }\end{array}$ & $\begin{array}{c}\text { p- } \\
\text { value }\end{array}$ \\
\hline $\begin{array}{c}\text { Pre- } \\
\text { test }\end{array}$ & 3.128 & 0.4589 & 3.0733 & 0.4608 & 3.3683 & 0.5165 & 3.128 & 0.4589 & .3339 \\
\hline
\end{tabular}

Finally, we also wanted to investigate if there was any growth in the level of autonomy within particular groups. Once more the two-way ANOVA was implemented. Once more the two-way ANOVA was implemented, the results of which are presented in the table below: 
Table 2. One-way ANOVA for the pre-test and post-test results in all four groups

\begin{tabular}{|c|c|c|c|c|c|c|}
\hline & $\begin{array}{c}\text { Pre-test } \\
\text { mean }\end{array}$ & Std. Dev. & $\begin{array}{c}\text { Post-test } \\
\text { mean }\end{array}$ & Std. Dev. & p-value & $\begin{array}{c}\text { Mean } \\
\text { difference }\end{array}$ \\
\hline Control group & 3.1286 & 0.4599 & 3.3762 & 0.5147 & .1757 & +0.25 \\
\hline Flipped classroom & 3.0733 & 0.4608 & 3.5927 & 0.411 & .0029 & +0.52 \\
\hline Project work & 3.3667 & 0.5169 & 3.6917 & 0.4504 & .077 & +0.32 \\
\hline WebQuest & 2.9107 & 0.4519 & 3.5333 & 0.5035 & .0013 & +0.62 \\
\hline
\end{tabular}

Source: own research

The p-value for the control group and the project workgroup is higher than .05 thus the shift in their level of autonomy is not statistically significant. Whereas the one-way ANOVA results (where $\mathrm{p}<.05$ ) for the flipped classroom group and the WebQuest group indicate that their growth of autonomy was relevant from the statistical point of view.

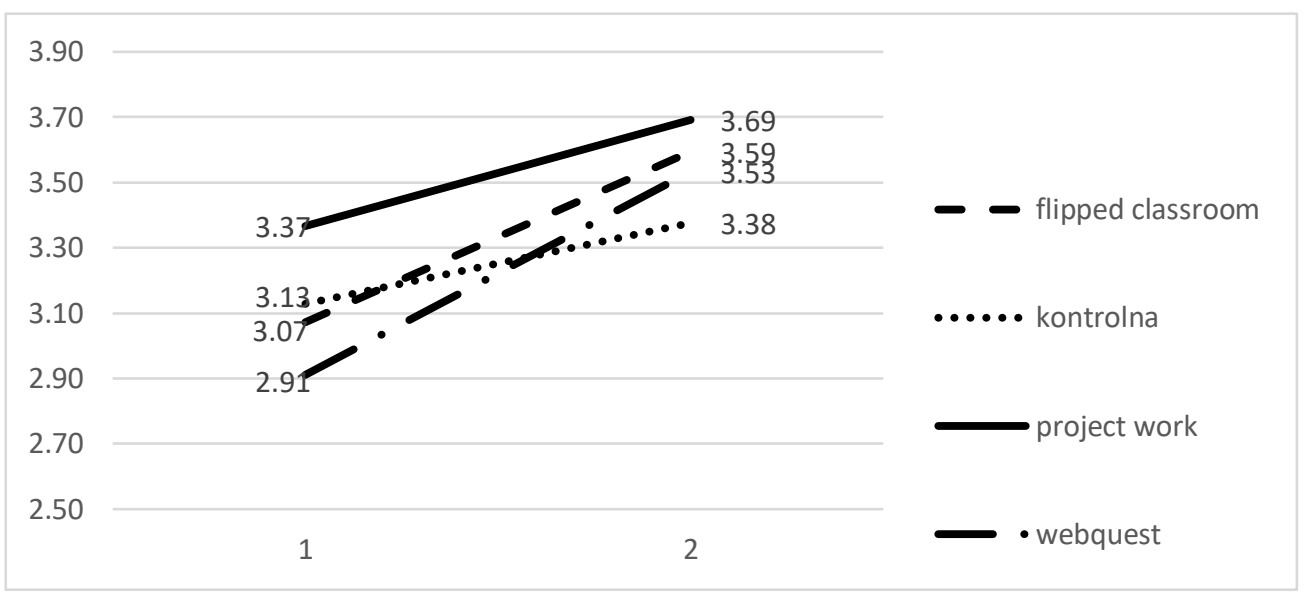

Figure 1. The comparison of the mean scores for each of the four groups

The graph above compares the mean scores for each of the four groups in the first and second measurements. It is worth noting that there is an improvement in the average score in each of the groups. The greatest increase was recorded in the WebQuest group and the smallest in the control group.

\subsection{Results of the quantitative study concerning learners' writing skills}

Before the quasi-experimental treatment was introduced, the students had been asked to complete a writing assignment which served as a pre-test in the second stage of the research. The test had a form of the Matura exam writing task. The students' e-mails were assessed and the points were granted in four categories, namely content, coherence and internal logic, linguistic diversity, and linguistic accuracy.

After the intervention had been finished, the students were given another assignment, the assumptions of which were similar. The assessment guideline applied in this case was the same as in the previous assignment and was adapted from the technical manual for examiners and teachers published on the Central Examination Board website. 
The results of assignments, the pre-test, and the post-test were collected and analyzed. The one-way ANOVA outcome was first performed to assess if the results from the pre-test varied significantly. The outcome of the test is presented in the table below:

Table 3. ANOVA results for pre-test

\begin{tabular}{|c|c|c|c|c|}
\hline & Control group & Flipped classroom & Project work & WebQuest \\
\hline $\mathrm{N}$ & 14 & 12 & 16 & 15 \\
\hline Mean & 8.7143 & 7.9167 & 8.9375 & 8.6 \\
\hline Std.Dev. & 1.7289 & 1.2401 & 1.0626 & 1.2984 \\
\hline p-value & \multicolumn{4}{|c|}{.2557} \\
\hline
\end{tabular}

Source: own research

The outcome of the test revealed that the mean values were not significantly different as $p$ equals .2557 and were higher than .05 . In other words, the students got mostly a very similar number of points in the pre-test.

Similarly, the results from the post-test were collected and analyzed in the same manner. The one-way ANOVA results were as follows:

Table 4. ANOVA results for post-test

\begin{tabular}{|c|c|c|c|c|}
\hline & Control group & Flipped classroom & Project work & WebQuest \\
\hline $\mathrm{N}$ & 14 & 12 & 16 & 15 \\
\hline Mean & 9.3571 & 8.75 & 9.5 & 9.6667 \\
\hline Std.Dev. & 0.9288 & 1.0553 & 0.8165 & 0.488 \\
\hline p-value & \multicolumn{2}{|c|}{.04} \\
\hline
\end{tabular}

The p-value obtained in the test was less than .05 which meant that the mean samples of the studied groups differ significantly. However, to learn which samples differ and to what extent a post hoc test had to be conducted. The Tukey's HSD (honestly significant difference) test was chosen as it allows for pairwise comparisons within the ANOVA data. The results evidenced that the discrepancy between the post-test outcome in the flipped classroom group and the WebQuest group is the most significant with the p-value at .0262, which implies that the WebQuest experimental group students obtained a larger number of points than the ones who were assigned to the flipped classroom group. The mean difference was .92 .

Finally, we compared the outcomes of the pre-test and the post-test within each group. Ttest could not be used in this case as the samples were not normally distributed. Hence, a oneway ANOVA was carried out for each one of them. The results are presented below:

Table 5. ANOVA test results for each of the groups

\begin{tabular}{|c|c|c|c|c|c|c|c|}
\hline & \multirow{2}{*}{$\mathrm{N}$} & \multicolumn{2}{|c|}{ Pre-test } & \multicolumn{2}{|c|}{ Post-test } & \multirow{2}{*}{$\begin{array}{c}p- \\
\text { value }\end{array}$} & \multirow{2}{*}{$\begin{array}{c}\text { Mean } \\
\text { difference }\end{array}$} \\
\hline & & Mean & Std.Dev. & Mean & Std.Dev. & & \\
\hline Control group & 14 & 8.7143 & 1.7289 & 9.3571 & 0.9288 & .2313 & +0.6428 \\
\hline Flipped classroom & 12 & 7.9167 & 1.2401 & 8.75 & 1.0553 & .0901 & +0.8333 \\
\hline Project work & 16 & 8.9375 & 1.0626 & 9.5 & 0.8165 & .1035 & +0.5625 \\
\hline WebQuest & 15 & 8.6 & 1.2984 & 9.6667 & 0.488 & .0059 & +1.0667 \\
\hline
\end{tabular}


The $\mathrm{p}$-value is less than .05 only in the case of the WebQuest group $(\mathrm{p}=.0059)$. Thus, although the mean differences in each of the groups, control and experimental, suggest that there was growth in the writing skills in all of the groups, only the result obtained by the WebQuest group is statistically significant.

\subsection{Discussion}

The data collected in the pre-and post-test suggests, that the WebQuest methodology contributes to the development of learners' autonomy to the greatest extent. The mean difference between the first measurement and the second one was 0.62, points and the result was statistically significant. Similarly, the flipped classroom group's increase in the level of autonomy was substantial and amounted to 0.52 points, which was relevant from the statistical point of view. The growth in autonomy noted in the project workgroup was not statistically significant, however, those students reached the highest level of autonomy after the intervention had finished. Although according to the ANOVA performed for the pre-test in all four groups there were no relevant differences between the groups at the beginning of the study, [Figure 1] shows that the project workgroup students' level of autonomy was also the highest at the beginning of the study. Hence, they had already had some abilities which their friends needed to acquire. In conclusion, two out of three experimental groups achieved a significantly higher level of autonomy, nevertheless, the findings of the study might be perceived as inconclusive. Wong et al. [17] in their study concentrating on the effect of BL learning on developing learners' autonomy drew similar conclusions. His observations stood in strong opposition to the results of his study. However, although there was no relevant difference in the level of autonomy between the experimental and control group, he still believed that implementing technology into EFL teaching in the form of BL contributes to more effective work during classes.

The aim of the study expressed in the first research sub-questions related to the students' developing reactive autonomy (or semi-autonomy) and proactive autonomy. The findings suggest that self-direction was acquired best in the teaching paradigms which assumed teacher guidance, i.e., in the flipped classroom and WebQuest teaching. In the case of WebQuests, the learners were given the pre-selected materials, were informed about the objectives and the form of evaluation of their work. They were mostly supposed to organize the learning process to fit their needs. The situation was similar with the flipped classroom group as the materials they used in class and outside of it were designed or chosen by the teacher. The only difference is that there were some possibilities of choosing a task during classes. According to Littlewood [7], the ability to plan and organize one's learning, once the goal and directions had been determined, is the indicator of growing autonomy. Students who are not used to independent work feel more secure when they are gradually encouraged to take responsibility for their learning. Although the Polish context differs from the Asian one, the authoritarian teaching style, as noticed by Batyra [12], is frequently present in language classes. Thus, the shift from full dependence and obedience to full independence is a timeconsuming process, the implementation of which would be challenging in the traditional approach to teaching. Blended learning, however, facilitates a gradual change in the students' level of autonomy. To conclude, the findings support the stance that in this case, BL activities worked more efficiently in developing students' reactive autonomy.

The study was supposed to establish if the flipped-classroom approach to teaching and learning has a positive impact on developing learners' autonomy. The platform used to share the learning materials with the students was MS Teams and the materials themselves included 
YouTube videos, some articles available on various websites, and some online language activities. As has already been mentioned, flipped classroom approach implemented in the quasi-experimental treatment helped students to develop autonomy. The mean value of the pre- test and the post-test differed by 0.52 points and the result was statistically significant. The answers given in the autonomy questionnaire suggest that the students can better identify their language needs. Moreover, it turned out that they more often choose the study materials on their own and do not limit themselves to those recommended by the teacher. They better know the effects of the way they learn and can modify it if necessary. They can also decide what the most important things during the English lessons are for them. It can be, thus, concluded that flipped classroom teaching model may be a valuable tool for fostering the growth of autonomy in secondary school learners.

The researchers wanted to know if WebQuests can constitute a beneficial approach to teaching aimed at developing learners' autonomy. The outcome of the study suggests that WebQuests are useful when it comes to fostering students' independence. The mean difference between the first measurement and the second one was 0.62 points $(p=0.0013<$ $.05)$, which made WebQuest teaching and learning the most successful intervention. The students' scores indicated that they know their strengths and weaknesses in language learning better. They realize how to identify their own needs and improve at setting their language goals. It is also easier for them to decide, what the most important aspects of the classes are for them. They believe they can become fluent English speakers in the future more than before the experimental treatment was introduced. Overall, the WebQuest teaching practice proved to be effective in enhancing students' autonomy.

The question of the positive influence of project work on learners' autonomy can be arguable. The study findings evidenced that the growth in learners' autonomy was not statistically significant with the mean difference between measurements equalling 0.32 points $(\mathrm{p}=0.77>.05)$. However, the researchers' observations and some of the findings contradict the general outcome of the survey. During classes, the students were mostly motivated and willing to participate. The project group students were the ones who gladly did extra homework. Moreover, in the study, it could be noted that they believe they improved in assessing their language progress. They also grew better at evaluating the effectiveness of the way they work. They also learned how to modify it. Although the results of the study are ambiguous, the researchers believe that project work is a valuable tool for enhancing learners' autonomy.

The last of the research questions posed at the beginning of the study related to students' writing abilities. The authors wanted to know if the increased level of autonomy would affect learners' proficiency in writing. The results of the study in this aspect are inconclusive. Although the post-test results are slightly higher than the results of the pre-test, they are not statistically significant. It ought to be noted, though, that the group that improved their writing skills the most (mean difference: 1.07) was the WebQuest group, the members of which developed their autonomy to the largest extent.

Overall, although the results are inconclusive, blended learning activities are a valuable option in the EFL class. Similarly, to the findings of Saeheng [18], we learned that incorporating a blend of conventional classes and new technologies met the students' expectations to a great extent and positively influenced their motivation level, which, as noted by Güneş et al. [19], is closely correlated with autonomy since the more motivated they get, the more autonomous they become. What is more, BL fosters learners' autonomy and became a starting point for the popularisation of the idea of life-long learning. 


\subsection{Limitations of the study}

The most problematic challenge that needed to be faced by the researchers and the students was the Covid-19 pandemic. Its outbreak resulted in the introduction of distance learning in Poland. The study was designed to take place in the classroom and the use of technology was supposed to be another element of the "blend". However, all of the lessons had to take the form of online classes; thus, the whole premise of the quasi-experiment became arguable. It affected the writing part of the study to the greatest extent as working from home the students were tempted to use the online resources to help themselves in accomplishing the writing tasks. Moreover, the control group students spent more time working with online resources than they were supposed to.

The limits on the use of technology were questionable. The students are acquainted with the technology in EFL classes since it would be impossible to teach listening without using a CD player or a computer with speakers. However, it is the "how" that would make the difference in this case. Additionally, it is frequently assumed that teaching the so-called "digital natives" enables the teachers to use any sophisticated technology they can think of. However, as noted by Esfandiari et al. [20], the students find it much easier to engage with new technologies for the pursuit of entertainment than for educational reasons. It is thus argued that proper guidance should be provided for those who struggle.

\section{Conclusion}

Our main goal was to assess the usefulness of the blended learning environments in fostering learning autonomy. Moreover, we wanted to check which BL technique - flipped classroom, project work, or WebQuest method - would be the most effective. Although the outcome of the research is inconclusive, we remain avid enthusiasts of the BL approach to teaching and learning English. Apart from the fact that it allows the students to develop autonomy, it makes the classes more attractive for the students in numerous ways.

Using a blend of traditional but still more learner-centered approach and technology enables the students to make their own small choices during classes e.g., what dictionary to use or which website to visit to find a particular piece of information. Such an approach allows them gradually to develop independence, which is indispensable for those who intend to indulge in life-long learning.

Blended learning also increased the level of motivation in students as they can make their own choices, set their objectives, and make their plans. In today's world being independent, inner-directed, and motivated are the qualities that will help the students to achieve their goals, not only the linguistic ones.

\section{References}

[1] H. Holec, "Autonomy and foreign language learning," Oxford: Pergamon Press

[2] J. Bersin, "The blended learning book: Best practices, proven methodologies, and lessons learned," USA: Pfeiffer John Wiley \& Sons, Inc., (2004)

[3] D. Little, "Learner autonomy. 1: Definitions, issues, and problems," Dublin: Authentik

[4] P. Benson, "Teaching and researching autonomy," Harlow: Pearson Education Limited, (2011)

[5] J. Huang, (Peter), and P. Benson, "Autonomy, agency, and identity in foreign and second language education," Chinese Journal of Applied Linguistics, vol.36, no.1, pp.7-28, (2013), DOI:10.1515/cjal-2013-0002

[6] B. Sinclair, "Learner autonomy: The next phase?" In Sinclair, B., and McGrath, I. (Eds.), Learner autonomy, teacher autonomy: Future directions, pp.4-14, London: Longman, (2000) 
[7] W. Littlewood, "Defining and developing autonomy in East Asia contexts," Applied Linguistics, vol.20, no.1, pp.71-94, DOI:10.1093/applin/20.1.71

[8] L. Dickinson, "Culture, autonomy and common sense," In L. Dickinson (ed.) Autonomy 2000: The Development of Learning Independence in Language Learning. Conference Proceedings. Bangkok: King Mongkut's Institute of Technology Thonburi

[9] Z. Yang, "A study on self-efficacy and its role in mobile-assisted language learning," Theory and Practice in Language Studies, vol.10, no.4, pp.439, (2020), DOI:10.17507/tpls.1004.13

[10] P. Benson, “Teachers' and learners' perspectives on autonomy,” In T. Lamb, \& H. Reinders (Eds.), "Learner and teacher autonomy: Concepts, realities, and responses," pp.15-32, Amsterdam: John Benjamins, (2008)

[11] J. Wiertlewska, "Autonomization of the process of learning a foreign language, for example English as a manisfestation of trends in foreign language teaching in Poland in the area of transformation," Scripta Neophilologica Pos-naniensia X, pp.161-174, (2009)

[12] I. Batyra, "The perspective on learner autonomy in real teacher's practices in the context of higher primary polish EFL education," Roczniki Humanistyczne, vol.64, no.10, pp.53-81, (2016) DOI:10.18290/rh.2016.64.10-4

[13] M. Tayebinik and M. Puteh, "Blended learning or e-learning?" International Magazine on Advances in Computer Science and Telecommunications (IMACST), vol.3, no.1, pp.103-110, (2012)

[14] D. Marsh, "Blended learning. Creating learning opportunities for language learners," New York: Cambridge University Press, (2012)

[15] P. Ardi, "Promoting learner autonomy through Schoology m-learning platform in an EAP class at an Indonesian University,” Teaching English with Technology, vol.17, no.2, pp.70, (2017)

[16] M. Pawlak, (Ed.), “Autonomia w nauce języka obcego - co osiągnęliśmy i dokąd zmierzamy,” Poznań Kalisz - Konin: Adam Mickiewicz University Press and State School of Higher Professional Education in Konin Press, (2008)

[17] K. -T. Wong, G. -J. Hwang, P. S. Choo Goh, and S. K. Mohd Arrif, "Effects of blended learning pedagogical practices on students' motivation and autonomy for the teaching of short stories in upper secondary English," Interactive Learning Environments, vol.28, no.4, pp.512-525, (2018), DOI:10.1080/10494820.2018.1542318

[18] P. Saeheng, "A study of e-learning, blended learning, and traditional teaching methods to motivate autonomous learning in English reading comprehension of Thais learners," Indonesian Journal of English Language Teaching and Applied Linguistics, vol.2, no.1, pp.1, (2017), DOI:10.21093/ijeltal.v2i1.36

[19] S. Güneş and N. Alagözlü, "The interrelationship between learner autonomy, motivation and academic success in asynchronous distance learning and blended learning environments," Novitas-ROYAL (Research on Youth and Language), vol.14, no.2, pp.1-15, (2020)

[20] M. Esfandiari and M. W. Gawhary, "Is technology paving the way for autonomous learning?" World Journal of English Language, vol.9, no.2, pp.64, (2019) DOI:10.5430/wjel.v9n2p64 